\title{
BMJ Open Serum biomarkers in patients suspected of transient ischaemic attack in primary care: a diagnostic accuracy study
}

\author{
Louis Servaas Dolmans (D) , ${ }^{1}$ Frans Rutten, ${ }^{1}$ Marie-Louise E L Bartelink, ${ }^{1}$ \\ Ewoud J van Dijk, ${ }^{2}$ Paul J Nederkoorn, ${ }^{3}$ Jaap Kappelle, ${ }^{4}$ Arno W Hoes, ${ }^{1}$ The MIND- \\ TIA study group
}

To cite: Dolmans LS, Rutten F, Bartelink M-LEL, et al. Serum biomarkers in patients suspected of transient ischaemic attack in primary care: a diagnostic accuracy study. BMJ Open 2019;9:e031774. doi:10.1136/ bmjopen-2019-031774

- Prepublication history and additional material for this paper are available online. To view these files, please visit the journal online (http://dx.doi org/10.1136/bmjopen-2019031774).

Received 17 May 2019 Revised 18 September 2019 Accepted 19 September 2019

Check for updates

(c) Author(s) (or their employer(s)) 2019. Re-use permitted under CC BY-NC. No commercial re-use. See rights and permissions. Published by BMJ.

${ }^{1}$ Julius Center for Health Sciences and Primary Care, University Medical Center Utrecht, Utrecht University, Utrecht, The Netherlands ${ }^{2}$ Department of Neurology, Donders Centre for Neuroscience, Radboud University Medical Center, Nijmegen, The Netherlands ${ }^{3}$ Department of Neurology, Amsterdam University Medical Center, Amsterdam, The Netherlands

${ }^{4}$ Department of Neurology, University Medical Center Utrecht, Utrecht University, Utrecht, The Netherlands

Correspondence to

Dr Louis Servaas Dolmans; I.s.dolmans@umcutrecht.nl

\section{ABSTRACT}

Objective The diagnosis of transient ischaemic attack (TIA) based on symptoms and signs can be challenging and would greatly benefit from a rapid serum biomarker of brain ischaemia. We aimed to quantify the added diagnostic value of serum biomarkers in patients suspected of TIA beyond symptoms and signs. Methods This is a cross-sectional diagnostic accuracy study with a 6-month follow-up period. Participants were patients suspected of TIA by the general practitioner (GP) in whom a blood sample could be collected within 72 hours from symptom onset. A research nurse visited the participant for the blood sample and a standardised interview. The GP referred participants to the regional TIA service. An expert panel of three neurologists classified cases as TIA, minor stroke or any other diagnosis, based on all available diagnostic information including the GP's and neurologist's correspondence and the follow-up period. We used multivariable logistic regression analyses to quantify the diagnostic accuracy of clinical predictors and the improvement of accuracy by seven biomarkers (NR2, NR2 antibodies, PARK7, NDKA, UFD1, B-FABP and H-FABP)

Results 206 patients suspected of TIA participated, of whom $126(61.2 \%)$ were diagnosed with TIA $(n=104)$ or minor stroke $(n=22)$ by the expert panel. The median time from symptom onset to the blood sample collection was 48.0 (IQR 28.3-56.8) hours. None of the seven biomarkers had discriminative value in the diagnosis of TIA, with $\mathrm{C}$-statistics ranging from 0.45 to 0.58 . The final multivariable model (C-statistic 0.83 (0.78-0.89)) consisted of eight clinical predictors of TIA/minor stroke: increasing age, a history of coronary artery disease, sudden onset of symptoms, occurrence of symptoms in full intensity, dysarthria, no history of migraine, absence of loss of consciousness and absence of headache. Addition of the individual biomarkers did not further increase the C-statistics.

Conclusions Currently available blood biomarkers have no added diagnostic value in suspected TIA.

Trial registration number NCT01954329

\section{INTRODUCTION}

Symptoms suggestive of a transient ischaemic attack (TIA) often pose a diagnostic dilemma, and at the same time warrant
Strengths and limitations of this study

We recruited patients suspected of a transient ischaemic attack in the primary care setting, the domain in which we envision blood biomarkers to be most useful.

- A standardised interview by a research nurse provided detailed history taking, which was verified in the general practitioner's and neurologist's correspondence.

- We used as a reference standard a panel of three vascular neurologists, who reviewed all available diagnostic information, including a 6-month follow-up period.

- Transportation delay may have caused degradation by proteases of some of the biomarkers and therefore artificially overall lower values.

urgency as the risk of a subsequent ischaemic stroke is highest during the first hours and days following a TIA. ${ }^{12}$ A rapid and complete diagnostic assessment and urgent start of adequate treatment to prevent subsequent ischaemic stroke substantially decrease this risk, with the early initiation of an antithrombotic as the key intervention. ${ }^{3-5}$

The symptoms and signs of TIA are typically short-lasting (5-30 min) and have often disappeared by the time the patient consults a physician, often a general practitioner (GP). The diagnosis of TIA is mainly based on careful history taking and can be notoriously difficult for physicians. The differential diagnosis is broad and depends on symptoms and setting, with migraine and epileptic seizures as important TIA mimics. Especially, TIAs originating from the vertebrobasilar artery territory are often hard to distinguish from benign entities such as peripheral vestibular syndromes. MRI is recommended as imaging modality to confirm novel ischaemic lesions with diffusion weighted imaging. ${ }^{67}$ However, MRI is less widely available than CT, and still a minority of patients with suspected TIA have 
relevant lesions on MRI $(30 \%-40 \%) .{ }^{67}$ In primary care, the GP has the difficult task to decide, based on history taking only, whether the patient should be referred to the neurologist.

In patients referred by the GP to a TIA service, the diagnosis of TIA is confirmed by neurologists in around $70 \%$ of cases. ${ }^{8-10}$ However, also the neurologist is not always sure; in about a quarter of cases, the definite diagnosis by the neurologist holds a degree of uncertainty, that is, the neurologist concludes that a TIA is probable or possible. ${ }^{11}$ Even among experienced neurologists, there is substantial interobserver disagreement in TIA diagnosis, with Cohen's kappa statistics varying from 0.65 to $0.78 .^{8}$

A possible solution to these diagnostic difficulties would be a serum biomarker that can reliably detect (transient) brain ischaemia in an early phase after symptom onset. This would enable a more accurate diagnosis within a short time frame. We designed the MIND-TIA (Markers in the Diagnosis of TIA) study to evaluate markers of brain ischaemia for this purpose. ${ }^{12}$ We performed a systematic review to select candidate markers that can be detected in blood immediately after a TIA and remain detectable until several days after. ${ }^{12}{ }^{13}$ Previous clinical biomarker studies in the field of cerebral ischaemia focused on (major) stroke, and most studies compared patients with stroke with healthy volunteers, and thus did not evaluate the biomarkers in patients suspected of cerebral ischaemia, the domain of clinical interest. ${ }^{13}$

In the current study we aimed to assess the added diagnostic value of serum biomarkers in addition to symptoms and signs in patients suspected of TIA.

\section{METHODS}

We described the design and methods of the MIND-TIA study in detail elsewhere. ${ }^{12}$ In short, the MIND-TIA study was a cross-sectional diagnostic study, with an additional follow-up period of 6 months. Participants were patients suspected of a TIA by their GP who were referred to a TIA service. In all participants we performed a biomarker assessment (index test), and the 'definite' diagnosis of TIA was determined by a panel of three experienced stroke neurologists (the reference standard), who based their consensus opinion on all available diagnostic information, including imaging of the brain and the 6 months of follow-up, but excluding the information from the biomarkers.

\section{Study population}

From September 2013 until September 2016, we included patients with a new (not necessarily first) episode of symptoms or signs suspected of a TIA by their GP. Patients were eligible if a blood sample could be collected within 72 hours of symptom onset. Patients were recruited immediately after GP consultation or during their visit at the TIA outpatient clinic. Over 350 GPs and 11 TIA outpatient clinics in the region of Utrecht (the Netherlands) participated. Patients were excluded if (1) they still had active symptoms or signs at the time of recruitment (ie, during consultation of the GP) and therefore were suspected of an ongoing stroke; (2) blood could not be drawn within 72 hours; (3) valid history taking was impossible because of severe cognitive impairment or insufficient knowledge of the Dutch language; or (4) life expectancy was less than 6 months.

\section{Main study procedures}

A research nurse visited the participant at home or at the TIA outpatient clinic to draw a blood sample as soon as possible after inclusion. Additionally, the research nurse interviewed the patient and filled out a standardised case record form (CRF) on symptoms and signs. Following routine care, the GP referred participants to the regional TIA outpatient clinic. We collected all correspondence of the GP and the neurologist at the TIA service, including the results of additional investigations. At the participating TIA services, every participant had electrocardiography (ECG), a carotid duplex scan and a CT of the brain; Holter ECG, CT angiography or MRI of the brain was performed when indicated (MRI of the brain in approximately $20 \%$ of cases). After 6 months we scrutinised the electronic medical files of the GP for recurrent cerebrovascular and cardiovascular events, and other episodes of symptoms relevant to the diagnosis of the initial event.

\section{Panel diagnosis}

An expert panel of three vascular neurologists evaluated standardised case summaries based on the CRF (including medical history, initial signs and symptoms, and the patient's own narrative account of symptoms), GP's and neurologist's correspondence, and the 6 months of follow-up. Without knowledge of the biomarker values, cases were classified as a TIA, a minor ischaemic stroke or any other diagnosis. The panel primarily applied the time-based definition of TIA (symptoms lasting $<24$ hours).${ }^{14}$ However, for each case the panel also determined if neuroimaging (CT and/or MRI) showed ischaemic lesions corresponding with this symptom episode.

The panel members assessed all cases individually, providing both their most likely diagnosis and their estimation of the chance of a TIA on a Visual Analogue Scale (VAS). Consensus on the diagnosis of TIA was assumed if all three neurologists similarly scored the chance of TIA $\leq 20 \%$ or $\geq 80 \%$. All other cases were discussed during a panel meeting, and a final judgement was based on a majority of votes. At the end of the study we informed the treating GP about the panel diagnosis.

\section{Biomarker assessment}

We assessed the following biomarkers in serum: NR2, NR2 antibodies (NR2Ab), B-FABP, H-FABP, NDKA, UFD1 (all by sandwich ELISA procedures) and PARK7 (by Luminex assay procedure) (see online supplementary file 1 for the main characteristics of these biomarkers). The Laboratory of Clinical Chemistry and Haematology 
of the University Medical Center Utrecht performed the measurements, without knowledge of the panel outcome.

NR2 and NR2Ab were measured using the Gold Dot NR2 Peptide Test and Gold Dot NR2 Antibody Test (CIS Biotech, Decatur, USA). The lower limits of detection (LOD) were $0.1 \mathrm{ng} / \mathrm{mL}$ and $0.8 \mathrm{ng} / \mathrm{mL}$, respectively.

B-FABP, NDKA and UFD1 were measured with the FABP7 ELISA (EKU04045), NME1 ELISA (EKC34865) and UFD1L ELISA (EKC35975) from Biomatik (Cambridge, Ontario). For B-FABP, the LOD was $0.2 \mathrm{ng} /$ $\mathrm{mL}$, and the interassay variation at $0.40 \mathrm{ng} / \mathrm{mL}$ was $11.0 \%$. For NDKA, the LOD was $10 \mathrm{pg} / \mathrm{mL}$, and the interassay variation at $40 \mathrm{pg} / \mathrm{mL}$ was $10.1 \%$. For UFD1, the lower LOD was $62.5 \mathrm{pg} / \mathrm{mL}$, and the interassay variation was $<14 \%$. H-FABP was measured using the FABP3 ELISA (RAB0657) from Merck Sigma-Aldrich (St Louis, Missouri, USA). The LOD was $8 \mathrm{ng} / \mathrm{mL}$, and the interassay variation was $<11.5 \%$.

PARK7 was measured using a beads-based multiplex immunoassay. The Bio-Plex 200 Systems (Bio-Rad\#171000201) were used for measurement and data analysis. The limit of quantitation for PARK7 was $100 \mathrm{pg} / \mathrm{mL}$, and the interassay variation was $<5.3 \%$.

\section{Data analysis}

All diagnostic variables of routine clinical assessment (symptoms and signs) of the GP and the (mean and median) biomarker values are presented for subjects with a TIA or minor stroke and subjects with other diagnoses. Biomarker levels of both groups were compared using Mann-Whitney U tests. Three biomarkers showed test results below the detection range. In these cases, we assigned in our database a biomarker level fixed at $50 \%$ of the LOD, and we present the mean and median values of only those patients with values within the detection range in a separate table.

Diagnostic accuracy measures were assessed for both clinical characteristics and biomarkers. We created receiver operating characteristic (ROC) curves and used the Youden index to determine the optimum cut-off of the biomarkers assuming an equal cost of misdiagnosis in each direction, and we present corresponding accuracy data.

We performed multivariable logistic regression analyses to quantify the diagnostic accuracy of the strongest predictors of the clinical assessment (excluding additional examinations), and aimed to determine the improvement of diagnostic accuracy by adding biomarker assessment to these clinical determinants. Biomarkers with skewed distributions were logarithmically transformed before logistic regression analyses. Harrell's rule of thumb was applied to determine the maximum number of determinants in our final multivariate model, that is, one determinant per 10 subjects in the smallest category of the outcome value (in our situation patients without TIA/minor stroke). ${ }^{15}$ In the multivariable analysis, we used stepwise backwards selection of variables, with a cut-off of $\mathrm{p}<0.10$.

\section{Patient and public involvement}

There were no patients or public involved in the design or conduct of this study. The participants of the study will be informed about the main findings of the MIND-TIA study in general (those who signed up for this).

\section{RESULTS}

A total of 242 potentially eligible patients were announced to the research team by telephone by the GP or via TIA services. Fifteen patients needed to be excluded due to (1) onset of symptoms more than 72 hours ago $(n=7)$, (2) ongoing symptoms $(\mathrm{n}=6)$ or (3) severe cognitive impairment $(n=2)$. Eight patients decided not to participate after receiving detailed study information. In 13 additional patients it was not possible to plan a visit by the research nurse within 72 hours from symptom onset due to logistical reasons. The characteristics of the 206 included patients are shown in table 1.

The expert panel diagnosed 126 of 206 (61.2\%) patients with a TIA $(n=104)$ or minor stroke $(n=22)$. Five of the 104 patients with TIA (according to the criterion of symptoms lasting <24hours) had (corresponding) ischaemic lesions on brain imaging. Among the 80 patients with alternative diagnoses, most were labelled as migraine $(\mathrm{n}=24,30.0 \%)$, stress-related or somatoform symptoms $(\mathrm{n}=16,20.0 \%)$, and syncope $(\mathrm{n}=9,11.3 \%)$ (table 2). There was no association between sex and final TIA diagnosis. In total, 14 (6.8\%) patients (all patients with TIA/ minor stroke) suffered from a recurrent cerebrovascular event in the 6-month follow-up period, including 4 ischaemic strokes and 12 TIAs.

In 87 of 206 (42.2\%) cases the individual assessments by the panel members resulted in consensus on the presence (three VAS estimates of $\geq 80 \%$ ) or absence (three VAS estimates of $\leq 20 \%$ ) of TIA/minor stroke. The remaining 119 cases were discussed during panel meetings. In 51 of 119 cases the initial individual judgements on the most likely diagnosis were incongruent. In 14 cases disagreement remained after the panel discussion, and the majority vote (two against one) was decisive. The Fleiss' kappa was 0.90 for the complete expert panel process. We resampled 20 cases for blinded reassessment by the panel, and in 18 cases they decided uniformly, while in 2 cases their final panel judgement was inconsistent with the original diagnosis. Table 3 compares the panel diagnosis with the diagnosis of the treating neurologist.

The median time from symptom onset to the blood sample collection was 48.0 (IQR 28.3-56.8) hours. Subsequently, the time until the start of sample preparation and sample storage was $1.4(1.2-1.7)$ hours and 2.6 (2.52.7) hours, respectively. In one patient it was technically unable to draw a blood sample.

Table 4 shows the mean and median values of all biomarkers tested in patients with TIA or minor stroke and those with alternative diagnoses. Only H-FABP showed on average higher levels in patients with TIA/ minor stroke. Three biomarkers had a high number of 
Table 1 Characteristics of the 206 participants suspected of TIA by the GP, divided by the final diagnosis of the expert panel

\begin{tabular}{|c|c|c|c|c|}
\hline Characteristics & $\begin{array}{l}\text { Total } \\
\text { (N=206) }\end{array}$ & $\begin{array}{l}\text { TIA/minor } \\
\text { stroke } \\
(n=126)\end{array}$ & $\begin{array}{l}\text { No TIA/ } \\
\text { minor } \\
\text { stroke } \\
(n=80)\end{array}$ & $\begin{array}{l}P \\
\text { value }\end{array}$ \\
\hline \multicolumn{5}{|c|}{ Demographic characteristics } \\
\hline $\begin{array}{l}\text { Mean age in years } \\
\text { (SD) }\end{array}$ & $67.7(13.7)$ & $71.4(12.0)$ & $62.0(14.2)$ & $<0.001$ \\
\hline Male sex & $\begin{array}{l}112 \\
(54.4 \%)\end{array}$ & $69(54.8 \%)$ & $43(53.8 \%)$ & 0.89 \\
\hline
\end{tabular}

\section{Cardiovascular risk factors}

BMI in $\mathrm{kg} / \mathrm{m}^{2}$ (SD) $25.7(4.0) \quad 25.7$ (4.2) $\quad 25.6(3.8) \quad 0.85$ Smoking status

\begin{tabular}{|c|c|c|c|c|}
\hline Current smoker & $38(18.5 \%)$ & $18(14.3 \%)$ & $20(25.0 \%)$ & 0.05 \\
\hline Former smoker & 87 (42.2\%) & 58 (46.0\%) & $29(36.3 \%)$ & 0.17 \\
\hline Never smoked & $81(39.3 \%)$ & $50(39.7 \%)$ & $31(38.7 \%)$ & 0.89 \\
\hline $\begin{array}{l}\text { Alcohol } \\
\text { consumption, } \\
\text { units/week }\end{array}$ & $(n=205)$ & $(n=125)$ & $(n=80)$ & \\
\hline $0-7$ & $\begin{array}{l}143 \\
(69.8 \%)\end{array}$ & $89(71.2 \%)$ & 54 (67.5\%) & 0.63 \\
\hline $8-14$ & 37 (18.0\%) & $22(17.6 \%)$ & 15 (18.8\%) & 0.83 \\
\hline$>14$ & $25(12.2 \%)$ & $14(11.2 \%)$ & $11(13.7 \%)$ & 0.59 \\
\hline $\begin{array}{l}\text { First-degree } \\
\text { relatives with CVD } \\
\text { below } 65 \text { years }\end{array}$ & $(n=204)$ & $(n=125)$ & $(\mathrm{n}=79)$ & \\
\hline 0 & $\begin{array}{l}127 \\
(62.3 \%)\end{array}$ & $84(67.2 \%)$ & 43 (54.4\%) & 0.07 \\
\hline 1 & 59 (28.9\%) & $29(23.2 \%)$ & $30(38.0 \%)$ & 0.02 \\
\hline$\geq 2$ & $18(8.8 \%)$ & $12(9.6 \%)$ & $6(7.6 \%)$ & 0.62 \\
\hline Hypertension & $121(59 \%)$ & 84 (66.7\%) & $36(45.0 \%)$ & 0.002 \\
\hline Diabetes mellitus & 27 (13\%) & $18(14.3 \%)$ & $8(10.0 \%)$ & 0.37 \\
\hline Hyperlipidaemia & $85(42 \%)$ & $58(46.0 \%)$ & 27 (33.8\%) & 0.08 \\
\hline \multicolumn{5}{|l|}{ Medical history } \\
\hline $\begin{array}{l}\text { Cerebrovascular } \\
\text { disease }\end{array}$ & $51(24.8 \%)$ & 35 (27.8\%) & $16(20.0 \%)$ & 0.21 \\
\hline TIA & $31(15.0 \%)$ & $22(17.5 \%)$ & $9(11.3 \%)$ & 0.22 \\
\hline $\begin{array}{l}\text { Ischaemic } \\
\text { stroke }\end{array}$ & $22(11 \%)$ & 15 (11.9\%) & 7 (8.8\%) & 0.48 \\
\hline $\begin{array}{l}\text { Haemorrhagic } \\
\text { stroke }\end{array}$ & 7 (3\%) & $5(4.0 \%)$ & $2(2.5 \%)$ & 0.57 \\
\hline $\begin{array}{l}\text { Cardiovascular } \\
\text { disease }\end{array}$ & $54(26 \%)$ & $43(34.1 \%)$ & $11(13.8 \%)$ & 0.001 \\
\hline Angina pectoris & $13(6 \%)$ & $12(9.5 \%)$ & $1(1.3 \%)$ & 0.02 \\
\hline $\begin{array}{l}\text { Myocardial } \\
\text { infarction }\end{array}$ & $13(6 \%)$ & $13(10.3 \%)$ & $0(0.0 \%)$ & 0.003 \\
\hline $\begin{array}{l}\text { Peripheral artery } \\
\text { disease }\end{array}$ & $5(2 \%)$ & $4(3.2 \%)$ & $1(1.3 \%)$ & 0.38 \\
\hline Vascular surgery & $23(11 \%)$ & 19 (15.1\%) & $4(5.0 \%)$ & 0.03 \\
\hline Atrial fibrillation & $21(10 \%)$ & $15(11.9 \%)$ & $6(7.5 \%)$ & 0.31 \\
\hline Renal insufficiency & $16(8 \%)$ & $11(8.7 \%)$ & $5(6.3 \%)$ & 0.52 \\
\hline
\end{tabular}

Continued
Table 1 Continued

\begin{tabular}{|c|c|c|c|c|}
\hline Characteristics & $\begin{array}{l}\text { Total } \\
(\mathrm{N}=206)\end{array}$ & $\begin{array}{l}\text { TIA/minor } \\
\text { stroke } \\
(n=126)\end{array}$ & $\begin{array}{l}\text { No TIA/ } \\
\text { minor } \\
\text { stroke } \\
(n=80)\end{array}$ & $\begin{array}{l}P \\
\text { value }\end{array}$ \\
\hline Migraine & $23(11 \%)$ & $9(7.1 \%)$ & $14(17.5 \%)$ & 0.02 \\
\hline Epilepsy & $2(1 \%)$ & $2(1.6 \%)$ & $0(0.0 \%)$ & 0.26 \\
\hline
\end{tabular}

BMI, body mass index; CVD, cardiovascular disease; GP, general practitioner; TIA, transient ischaemic attack.

patients with biomarker values below the detection range: NR2Ab (47.8\%), NR2 (80.0\%) and B-FABP (93.7\%). In a separate table (table 5) we give an overview of the mean and median values of these three markers selectively in those with detectable values.

ROC curve analyses (table 6) and univariable regression analyses confirm that none of the seven markers has sufficient discriminative value in the diagnosis of TIA, with C-statistics ranging from 0.45 to 0.58 . Additional analyses taking into account the time from symptom onset to blood did not change the results.

Table 7 shows the results of univariable logistic regression analyses assessing the diagnostic value of separate clinical characteristics. The biomarkers proved to have no predictive value in the multivariable analyses, and we thus created an optimal clinical model with eight clinical determinants. The final multivariable model is shown in table 8 , and had a C-statistic of $0.83(0.78-0.89)$. The predictors of a diagnosis of TIA or minor stroke are (1) a higher age; (2) a history of coronary artery disease (angina or myocardial infarction); (3) a sudden onset of symptoms; (4) occurrence of symptoms in full intensity; (5) dysarthria; (6) no history of migraine; (7) absence of

Table 2 Overview of final diagnoses in 80 patients with no transient ischaemic attack or minor stroke according to the expert panel

\begin{tabular}{|c|c|}
\hline Diagnoses & n (\%) \\
\hline Migraine with aura & $24(30.0)$ \\
\hline Stress-related/functional/somatoform & $16(20.0)$ \\
\hline $\begin{array}{l}\text { Syncope (reflex syncope/orthostatic } \\
\text { hypotension) }\end{array}$ & $9(11.2)$ \\
\hline Non-focal transient neurological attack & $7(8.8)$ \\
\hline Vestibular syndrome & $5(6.2)$ \\
\hline Peripheral neuropathy & $2(2.5)$ \\
\hline Cranial nerve palsy & $2(2.5)$ \\
\hline Ocular disease & $2(2.5)$ \\
\hline $\begin{array}{l}\text { Other diagnoses: epileptic seizure, subdural } \\
\text { haematoma, pituitary adenoma, encephalopathy, } \\
\text { retinal spasms, sleep phenomena, amyloid spell } \\
\text { in cerebral amyloid angiopathy }\end{array}$ & $7(8.8)$ \\
\hline Unclear & $6(7.5)$ \\
\hline Total & 80 \\
\hline
\end{tabular}


Table 3 Panel diagnosis versus the diagnosis of the treating neurologist

\begin{tabular}{lll} 
& \multicolumn{2}{l}{$\begin{array}{l}\text { Diagnosis of the treating } \\
\text { neurologist }\end{array}$} \\
\cline { 2 - 3 } & $\begin{array}{l}\text { (Possible) TIA/minor } \\
\text { stroke treated as }\end{array}$ & $\begin{array}{l}\text { Other } \\
\text { diagnosis }\end{array}$ \\
Pach & 1 \\
\hline TIA/minor stroke & 125 & 50 \\
\hline Other diagnosis & 30 & \\
\hline
\end{tabular}

TIA, transient ischaemic attack.

loss of consciousness; and (8) absence of headache. As expected in view of the univariable analyses, adding the individual biomarkers, or a combination of biomarkers, to the clinical model did not improve the C-statistic.

\section{DISCUSSION}

Currently available blood biomarkers have no value in addition to clinical symptoms and signs in the diagnosis of TIA. A multivariate diagnostic model consisting of clinical determinants only had good diagnostic accuracy with a C-statistic of 0.83 (0.78-0.89).

Our study was the first to evaluate potential diagnostic serum biomarkers in a large clinical population of patients suspected of TIA. Evidence for the potential of our set of biomarkers was mainly based on studies comparing early biomarker levels in patients with major ischaemic stroke with levels in healthy individuals. ${ }^{12}$ Obviously, however, the value of diagnostic tests should be assessed in the relevant domain, that is, patients suspected of the
Table 5 Mean and median biomarker values of only those patients with detectable levels, for the three markers that showed marker levels below limit of detection

\begin{tabular}{llll}
\hline Biomarker & & $\begin{array}{l}\text { TIA/minor } \\
\text { stroke }\end{array}$ & $\begin{array}{l}\text { No TIA/minor } \\
\text { stroke }\end{array}$ \\
\hline NR2, $\mathrm{n}=41$ & $\mathrm{n}(\%)$ & $25(61.0)$ & $16(39.0)$ \\
& Mean (SD) & $1.03(2.60)$ & $1.48(2.78)$ \\
& Median (IQR) & $0.36(0.18-0.72)$ & $0.36(0.13-1.50)$ \\
NR2Ab, & $\mathrm{n}(\%)$ & $61(57.0)$ & $46(43.0)$ \\
$\mathrm{n}=107$ & Mean (SD) & $2.14(1.47)$ & $2.31(1.51)$ \\
& Median (IQR) & $1.60(1.15-2.70)$ & $1.70(1.10-3.60)$ \\
$\mathrm{B}-\mathrm{FABP}$, & $\mathrm{n}(\%)$ & $8(57.1)$ & $6(42.9)$ \\
$\mathrm{n}=14$ & Mean (SD) & $0.31(0.10)$ & $0.30(0.11)$ \\
& Median (IQR) & $0.28(0.25-0.36)$ & $0.26(0.22-0.41)$ \\
\hline
\end{tabular}

NR2Ab, NR2 antibodies; TIA, transient ischaemic attack.

disease of interest in daily practice. A comparison of biomarker levels in patients with a severe manifestation of the disease with the levels in healthy volunteers is both clinically irrelevant and bound to overestimate the diagnostic value in day-to-day clinical practice. For the interpretation of our results, it is important to realise that it is a much more challenging task for a biomarker to discriminate TIA/minor stroke (lower grades of ischaemia) from TIA-mimicking entities, because the tissue damage is less than in patients with major stroke and because the time to first medical consultation (and thus biomarker assessment) is in general much longer in patients suspected of TIA. Moreover, some of the biomarkers are more likely

\begin{tabular}{|c|c|c|c|c|}
\hline \multicolumn{2}{|c|}{ Biomarker* (unit of measurement) } & \multirow{2}{*}{$\begin{array}{l}\text { TIA/minor stroke } \\
\mathbf{n = 1 2 5} \\
0.25(0.03 \text { to } 0.46) \\
0.05 \text { (0.05 to } 0.05)\end{array}$} & \multirow{2}{*}{$\begin{array}{l}\begin{array}{l}\text { No TIA/minor stroke } \\
\mathbf{n = 8 0}\end{array} \\
0.34(0.04 \text { to } 0.64) \\
0.05(0.05 \text { to } 0.05)\end{array}$} & \multirow{2}{*}{$\begin{array}{l}\text { P value } \dagger \\
0.95\end{array}$} \\
\hline $\begin{array}{l}\mathrm{NR} 2 \\
(\mathrm{ng} / \mathrm{mL})\end{array}$ & $\begin{array}{l}\text { Mean }(95 \% \mathrm{Cl}) \\
\text { Median (IQR) }\end{array}$ & & & \\
\hline $\begin{array}{l}\text { NR2Ab } \\
\text { (ng/mL) }\end{array}$ & $\begin{array}{l}\text { Mean }(95 \% \mathrm{Cl}) \\
\text { Median (IQR) }\end{array}$ & $\begin{array}{l}1.48(1.15 \text { to } 1.82) \\
0.90(0.40 \text { to } 1.70)\end{array}$ & $\begin{array}{l}1.74(1.29 \text { to } 2.18) \\
1.0(0.40 \text { to } 2.10)\end{array}$ & 0.21 \\
\hline $\begin{array}{l}\text { PARK7 } \\
\text { (ng/mL) }\end{array}$ & $\begin{array}{l}\text { Mean }(95 \% \mathrm{Cl}) \\
\text { Median (IQR) }\end{array}$ & $\begin{array}{l}16.91(15.95 \text { to } 17.87) \\
16.61(13.42 \text { to } 19.77)\end{array}$ & $\begin{array}{l}18.11(16.63 \text { to } 19.59) \\
16.83(13.87 \text { to } 21.08)\end{array}$ & 0.37 \\
\hline $\begin{array}{l}\text { NDKA } \\
(\mathrm{pg} / \mathrm{mL})\end{array}$ & $\begin{array}{l}\text { Mean }(95 \% \mathrm{Cl}) \\
\text { Median (IQR) }\end{array}$ & $\begin{array}{l}68.64 \text { (60.19 to } 77.08) \\
52.70 \text { (35.80 to } 82.33)\end{array}$ & $\begin{array}{l}64.75 \text { (53.75 to } 75.44) \\
48.55 \text { (34.30 to } 80.35)\end{array}$ & 0.47 \\
\hline $\begin{array}{l}\text { UFD1 } \\
\text { (pg/mL) }\end{array}$ & $\begin{array}{l}\text { Mean }(95 \% \mathrm{Cl}) \\
\text { Median (IQR) }\end{array}$ & $\begin{array}{l}203.27(168.24 \text { to } 238.29) \\
153.00(30.00 \text { to } 307.00)\end{array}$ & $\begin{array}{l}211.70(168.03 \text { to } 255.37) \\
173.50(30.00 \text { to } 304.75)\end{array}$ & 0.72 \\
\hline $\begin{array}{l}\text { B-FABP } \\
\text { (ng/mL) }\end{array}$ & $\begin{array}{l}\text { Mean }(95 \% \mathrm{Cl}) \\
\text { Median (IQR) }\end{array}$ & $\begin{array}{l}0.11(0.10 \text { to } 0.12) \\
0.10(0.10 \text { to } 0.10)\end{array}$ & $\begin{array}{l}0.11(0.10 \text { to } 0.13) \\
0.10(0.10 \text { to } 0.10)\end{array}$ & 0.95 \\
\hline $\begin{array}{l}\mathrm{H}-\mathrm{FABP} \\
\text { (ng/mL) }\end{array}$ & $\begin{array}{l}\text { Mean }(95 \% \mathrm{Cl}) \\
\text { Median (IQR) }\end{array}$ & $\begin{array}{l}20.98(18.85 \text { to } 22.79) \\
19.70(13.83 \text { to } 27.00)\end{array}$ & $\begin{array}{l}20.21(15.53 \text { to } 24.77) \\
17.40(11.80 \text { to } 23.00)\end{array}$ & 0.05 \\
\hline
\end{tabular}

Biomarkers with median values set in italics had a high number of biomarker values below the detection range.

${ }^{*} \mathrm{NR} 2, \mathrm{NR} 2 \mathrm{Ab}$ and B-FABP showed test results below the detection range. These cases were assigned with a biomarker level fixed at $50 \%$ of the lower limit of detection.

†Biomarker levels of both groups were compared using Mann-Whitney $U$ tests.

NR2Ab, NR2 antibodies; TIA, transient ischaemic attack. 
Table 6 C-statistic of each biomarker and optimal sensitivity and specificity using the Youden index

\begin{tabular}{llllc}
\hline Biomarker & C-statistic $(\mathbf{9 5} \% \mathbf{C l})$ & Sensitivity & Specificity & Cut-off \\
\hline NR2 & $0.50(0.42$ to 0.58$)$ & 0.18 & 0.85 & $0.13 \mathrm{ng} / \mathrm{mL}$ \\
NR2Ab & $0.45(0.37$ to 0.53$)$ & 0.05 & 0.96 & $4.45 \mathrm{ng} / \mathrm{mL}$ \\
PARK7 & $0.46(0.38$ to 0.54$)$ & 0.64 & 0.39 & $15.23 \mathrm{ng} / \mathrm{mL}$ \\
NDKA & $0.53(0.45$ to 0.61$)$ & 0.37 & 0.75 & $74.90 \mathrm{pg} / \mathrm{mL}$ \\
UFD1 & $0.49(0.40$ to 0.57$)$ & 0.24 & 0.78 & $313.50 \mathrm{pg} / \mathrm{mL}$ \\
B-FABP & $0.50(0.42$ to 0.58$)$ & 0.06 & 0.96 & $0.22 \mathrm{ng} / \mathrm{mL}$ \\
H-FABP & $0.58(0.50$ to 0.66$)$ & 0.35 & 0.65 & $19.15 \mathrm{ng} / \mathrm{mL}$ \\
\hline
\end{tabular}

NR2Ab, NR2 antibodies.

to show increased values in TIA mimics than in healthy volunteers.

The diagnostic value of NR2 was previously evaluated in a population of patients with suspected stroke. In this study among 192 patients in whom 53\% indeed had a stroke, the negative and positive predictive values were $96.0 \%$ (95\% CI 92.3 to 98.3 ) and $93.0 \%$ (95\% CI 86.1 to 97.1), respectively. ${ }^{16}$ In our patient population of patients suspected of TIA/minor stroke (61\% TIA/minor stroke), $80.0 \%$ of patients had an NR2 value below the border of detection. Importantly, we measured NR2 in serum and not in plasma as is preferred because of degradation of NR2 by proteases during a longer preanalytic phase. However, this could only partly explain these results as it is estimated that serum measurements lead to approximately $30 \%$ lower values. Another difference is the total time to sample storage: a median of 2.6 hours in our study and a maximum of $30 \mathrm{~min}$ in the aforementioned study. ${ }^{16}$ Blood samples with the highest NR2 values (from patients with TIA as well as non-TIA patients), however, also had a time to storage of 3 hours. Overall, we could not detect a correlation between time to storage and the value of NR2. Sensitivity analysis of the subsample of patients with NR2 values above the detection level also showed that NR2 had no diagnostic value in our population (C-statistic $0.50)$. Unlike NR2, NR2Ab levels do not increase early after acute ischaemia. Previous studies suggested that NR2Ab levels rather reflect a history of (multiple) ischaemic cerebrovascular events. ${ }^{17}$ However, in our study we were unable to find a correlation between NR2Ab levels and either previous ischaemic cerebrovascular events or current TIA.

H-FABP was the only marker with on average higher values in patients with TIA/minor stroke compared with those with an alternative diagnosis. Still, with a C-statistic of 0.58 , the overall diagnostic accuracy of H-FABP was very low. As a comparison, the C-statistic of the variable age was 0.69. Neither in univariable nor multivariable logistic regression analyses H-FABP was a predictor of TIA/minor stroke.

B-FABP had only been evaluated as an early marker in patients with stroke in a study with serial measurements of both B-FABP and H-FABP in 42 patients with stroke, and a comparison with a control group (ideally patients suspected of stroke but who did not have the disease) was lacking. ${ }^{18}$ This study showed peak concentrations of both markers several hours after stroke, but also indicated B-FABP to be the least sensitive of the two. In our study the levels of B-FABP were below the detection level in the large majority of patients. Although the numbers are small, results in those with values in the detection range gave no indication of any discriminative value of B-FABP.

Previous studies evaluating the markers PARK7, NDKA and UFD1 suggested that levels equally increase in patients with TIA and in patients with major stroke, and that levels stay elevated for days. ${ }^{1920}$ Both high positive and negative predictive values were reported, however, with three rather divergent cut-offs used and in case-control studies with healthy volunteers as controls. In our clinical population the levels of all three biomarkers in patients with TIA/minor stroke were comparable with those in TIA-suspected patients with an alternative diagnosis.

The Dawson score and the Diagnosis of TIA (DOT) score have been proposed as diagnostic scores for TIA, but did not find their way to clinical practice. ${ }^{21} 22$ They were derived from logistic regression analyses and consist of 9 and 17 clinical determinants, respectively. The Dawson score showed poor results when applied by GPs (C-statistic 0.70). ${ }^{23}$ Similar to the Dawson and the DOT score, our final multivariable diagnostic model includes age, previous cardiovascular disease and individual symptoms that are positively or negatively associated with TIA (eg, loss of consciousness and headache are negative predictors of TIA in all three models). We also included variables on the course of symptoms in our analyses, and we show that a sudden onset of symptoms and an onset in full intensity (ie, no gradual progression of symptoms) are important predictors of a TIA. This once more underlines that careful history taking on the course of symptoms is crucial, and that such items should be included in attempts to create a useful diagnostic tool.

The main strengths of our study are the extensive information gathered per patient and the expert panel establishing the final diagnosis in a standardised manner. The use of an expert panel procedure can be criticised but is considered to be the best option to confirm a diagnosis 
Table 7 Univariable logistic regression analyses assessing the value of clinical characteristics in the diagnosis of TIA

\begin{tabular}{|c|c|c|}
\hline Variables & OR $(95 \% \mathrm{Cl})$ & $P$ value \\
\hline \multicolumn{3}{|l|}{$\begin{array}{l}\text { Demographic } \\
\text { characteristics }\end{array}$} \\
\hline Age per year & 1.06 (1.03 to 1.08$)$ & $<0.001$ \\
\hline Male sex & 1.04 (0.59 to 1.83$)$ & 0.89 \\
\hline \multicolumn{3}{|l|}{ Medical history } \\
\hline Cerebrovascular disease & 1.54 (0.79 to 3.01$)$ & 0.21 \\
\hline TIA & 1.67 (0.73 to 3.84$)$ & 0.23 \\
\hline Ischaemic stroke & 1.41 (0.55 to 3.62$)$ & 0.48 \\
\hline Haemorrhagic stroke & 1.61 (0.31 to 8.51$)$ & 0.57 \\
\hline CVD & 3.25 (1.56 to 6.78 ) & 0.002 \\
\hline Angina pectoris & 8.32 (1.06 to 65.25$)$ & 0.04 \\
\hline Myocardial infarction & $19.15^{\star}$ & 0.002 \\
\hline Peripheral artery disease & 2.60 (0.28 to 23.60$)$ & 0.40 \\
\hline Vascular surgery & 3.37 (1.10 to 10.32$)$ & 0.03 \\
\hline Renal insufficiency & 1.44 (0.48 to 4.30$)$ & 0.52 \\
\hline Atrial fibrillation & 1.67 (0.62 to 4.50$)$ & 0.31 \\
\hline Epilepsy & $3.23^{\star}$ & 0.52 \\
\hline Migraine & $0.36(0.15$ to 0.88$)$ & 0.03 \\
\hline
\end{tabular}

Cardiovascular risk factors

BMI per unit increase in $\mathrm{kg} / \quad 1.01$ (0.94 to 1.08$) \quad 0.85$ $\mathrm{m}^{2}$

\begin{tabular}{|c|c|c|}
\hline Smoking (ever vs never) & 1.04 (0.59 to 1.85$)$ & 0.89 \\
\hline $\begin{array}{l}\text { Alcohol consumption per } \\
\text { unit/week }\end{array}$ & 0.99 (0.96 to 1.03$)$ & 0.62 \\
\hline $\begin{array}{l}\text { Positive family history of } \\
\text { CVD } †\end{array}$ & 0.58 (0.33 to 1.04$)$ & 0.07 \\
\hline Hypertension & 2.44 (1.38 to 4.35$)$ & $<0.001$ \\
\hline Diabetes mellitus & 1.50 (0.62 to 3.63$)$ & 0.37 \\
\hline Hyperlipidaemia & 1.67 (0.94 to 2.99$)$ & 0.08 \\
\hline \multicolumn{3}{|l|}{ Course of symptoms } \\
\hline Duration of symptoms $\ddagger$ & 1.08 (0.93 to 1.25$)$ & 0.31 \\
\hline Sudden onset of symptoms & 2.43 (0.89 to 6.67$)$ & 0.09 \\
\hline Preceding symptoms & 0.69 (0.38 to 1.25$)$ & 0.23 \\
\hline $\begin{array}{l}\text { Occurrence of symptoms in } \\
\text { full intensity }\end{array}$ & 2.00 (0.95 to 4.19$)$ & 0.07 \\
\hline \multicolumn{3}{|l|}{ Type of symptoms } \\
\hline Motor symptoms & 2.33 (1.28 to 4.23$)$ & 0.01 \\
\hline Sensory symptoms & 1.45 (0.82 to 2.58$)$ & 0.20 \\
\hline Vision problem & 0.53 (0.29 to 0.97$)$ & 0.04 \\
\hline Blurred vision & 0.29 (0.12 to 0.73$)$ & 0.008 \\
\hline Diplopia & 0.46 (0.17 to 1.30$)$ & 0.14 \\
\hline Hemianopia & 0.84 (0.28 to 2.51$)$ & 0.75 \\
\hline Amaurosis fugax & 3.36 (0.72 to 15.76$)$ & 0.12 \\
\hline Communication problem & 1.35 (0.77 to 2.38$)$ & 0.29 \\
\hline Dysphasia & 0.99 (0.53 to 1.84$)$ & 0.98 \\
\hline
\end{tabular}

Continued
Table 7 Continued

\begin{tabular}{llc}
\hline Variables & OR $(95 \%$ Cl) & P value \\
\hline Dysarthria & $1.71(0.80$ to 3.68$)$ & 0.17 \\
\hline Positive visual phenomena & $0.25(0.10$ to 0.61$)$ & 0.002 \\
Vertigo & $0.77(0.39$ to 1.54$)$ & 0.46 \\
Disturbed balance or gait & $1.14(0.57$ to 2.28$)$ & 0.71 \\
\hline Headache & $0.33(0.18$ to 0.60$)$ & $<0.001$ \\
Light-headedness & $0.66(0.37$ to 1.16$)$ & 0.15 \\
Palpitations & $0.31(0.11$ to 0.87$)$ & 0.03 \\
\hline Presyncope & $0.44(0.19$ to 1.07$)$ & 0.07 \\
\hline Loss of consciousness & $0.12(0.01$ to 1.05$)$ & 0.06 \\
\hline
\end{tabular}

*A Fisher's exact test was used in case of observed values of zero. $\dagger$ A positive family history was defined as $\geq 1$ first-grade family member with myocardial infarction, ischaemic stroke or peripheral artery disease $<65$ years of age.

‡Duration of symptoms in minutes was naturally log-transformed. BMI, body mass index; CVD, cardiovascular disease; TIA, transient ischaemic attack.

if an objective reference standard is lacking. Furthermore, the agreement was quite high for such a difficult clinical diagnosis; in only $14(6.8 \%)$ cases disagreement remained after panel discussions and the majority vote was decisive. The standardised interview by the research nurse provided detailed history taking of experienced symptoms and signs, which was verified in the GP's and neurologist's correspondence. This detailed information per case, including a narrative of the patient himself or herself, was crucial in the expert panel procedure.

The proportion of patients with TIA (ie, symptoms lasting <24hours) with ischaemic lesions proven with brain imaging is relatively low (5 out of 104). In our study participants were assessed following routine care, and

Table 8 Final multivariable logistic regression model of predictors of the diagnosis of TIA

\begin{tabular}{|c|c|c|}
\hline Variables & OR (95\% Cl) & $P$ value \\
\hline Age per year & 1.06 (1.03 to 1.09$)$ & $<0.001$ \\
\hline $\begin{array}{l}\text { History of coronary } \\
\text { artery disease* }\end{array}$ & 34.16 (3.39 to 344.03$)$ & 0.003 \\
\hline $\begin{array}{l}\text { Sudden onset of } \\
\text { symptoms }\end{array}$ & 2.72 (0.83 to 8.86$)$ & 0.098 \\
\hline $\begin{array}{l}\text { Onset of symptoms in } \\
\text { full intensity }\end{array}$ & 2.51 (0.94 to 6.71$)$ & 0.066 \\
\hline Dysarthria & $4.08(1.42$ to 11.73$)$ & 0.009 \\
\hline History of migraine & 0.24 (0.07 to 0.83$)$ & 0.024 \\
\hline Loss of consciousness & $0.03(0.01$ to 0.31$)$ & 0.003 \\
\hline Headache & $0.23(0.11$ to 0.48$)$ & $<0.001$ \\
\hline
\end{tabular}

Backward selection of variables was applied using a cut-off of $\mathrm{p}<0.10$.

C-statistic: 0.83 (0.78-0.89).

${ }^{*} \mathrm{~A}$ history of stable or unstable angina and/or myocardial infarction. TIA, transient ischaemic attack. 
thus only a minority of patients had an MRI of the brain, that is, the most sensitive imaging modality. Because we recruited patients in the home setting, we had blood transportation delay. This may have caused degradation by proteases of some biomarkers such as NR2 and therefore artificially overall lower values. On the other hand, when such biomarkers are applied in out-of-hospital settings, similar delays will occur.

Regarding our optimal clinical model, we acknowledge that the performance estimate we report is optimistic, as we did not further apply statistical methods to correct for overfitting. However, our objective was to assess whether the biomarkers could add information to the model. We did not intend to develop a reliable clinical model without the biomarkers.

Although the results of this study do not favour the use of biomarkers, the idea of a blood test providing evidence for transient cerebral ischaemia remains appealing. Translational research, including proteomic studies such as the recent SpecTRA study, ${ }^{24}$ will bring new biomarkers and perhaps also new sources of biomarkers. With our biobank of 206 well-phenotyped patients with suspected TIA, we created a valuable opportunity to easily evaluate or externally validate such new markers. Future studies evaluating biomarkers that are influenced by early degradation, like NR2, should consider immediate measurement by point-of-care tests in the outpatient setting. Furthermore, serial measurements in patients with TIA could gain more insight into the course of biomarker levels within the first days.

\section{CONCLUSIONS}

Our study shows that current blood biomarkers have no value in patients suspected of TIA. Among the most important clinical predictors of a TIA or minor stroke are a sudden onset of symptoms and an onset in full intensity.

Acknowledgements The MIND-TIA study is enabled by the collaboration of the Julius Center for Health Sciences and Primary Care with Saltro Diagnostic Center for Primary Care. We especially thank Saltro for providing the personnel and facilities necessary to realise prompt home visits and urgent blood processing.

Collaborators The MIND-TIA study group: LS Dolmans, Julius Center for Health Sciences and Primary Care, University Medical Center Utrecht, Utrecht University, Utrecht, The Netherlands; MEL Bartelink, Julius Center for Health Sciences and Primary Care, University Medical Center Utrecht, Utrecht University, Utrecht, The Netherlands; FH Rutten, Julius Center for Health Sciences and Primary Care, University Medical Center Utrecht, Utrecht University, Utrecht, The Netherlands; AW Hoes, Julius Center for Health Sciences and Primary Care, University Medical Center Utrecht, Utrecht University, Utrecht, The Netherlands; LJ Kappelle, Department of Neurology, Ural State Medical University, Yekaterinburg, Russia, and Department of Neurology, University Medical Center Utrecht, Utrecht University, Utrecht, The Netherlands; EJ van Dijk, Department of Neurology, Radboud University Medical Center, Nijmegen, The Netherlands; PJ Nederkoorn, Department of Neurology, Amsterdam UMC, University of Amsterdam, Amsterdam, The Netherlands; $S$ van Delft, Saltro Diagnostic Center for Primary Care, Utrecht, The Netherlands; GJ Seppenwoolde, Saltro Diagnostic Center for Primary Care, Utrecht, The Netherlands.

Contributors LSD is a PhD candidate and the primary researcher. LSD, FHR, MELB, AWH and LJK designed the study. LSD and FHR were the main contributors to the planning and conduct of the study. LSD performed the data collection and statistical analysis, under the supervision of FHR and MELB. LJK, PJN and EJvD contributed to the procedure of the expert panel diagnosis. LSD and FHR drafted the manuscript. MELB, AWH, LJK, EJvD and PJN have revised it critically and approved the manuscript.

Funding The primary researcher (LSD) performed this study as a general practitioner in training and combined his training with a PhD track. 'Stichting Beroepsopleiding Huisartsen (SBOH)', employer of Dutch GP trainees (financially), supported the PhD track. The Dutch foundation 'Stoffels-Hornstra' financially supported this study by a grant for performing the biomarker measurements. The funders had no involvement in the study design, the collection, analysis and interpretation of the data, the writing of the report, and the decision to submit the paper for publication.

Competing interests None declared.

Patient consent for publication Not required.

Ethics approval The MIND-TIA study has been approved by the Medical Research Ethics Committee of the University Medical Center of Utrecht, the Netherlands, on 5 September 2013 (protocol ID: 13/265), and was performed in accordance with the ethical standards laid down in the 1964 Declaration of Helsinki and its later amendments. Participants gave written informed consent.

Provenance and peer review Not commissioned; externally peer reviewed.

Data availability statement All data relevant to the study are included in the article or uploaded as supplementary information.

Open access This is an open access article distributed in accordance with the Creative Commons Attribution Non Commercial (CC BY-NC 4.0) license, which permits others to distribute, remix, adapt, build upon this work non-commercially, and license their derivative works on different terms, provided the original work is properly cited, appropriate credit is given, any changes made indicated, and the use is non-commercial. See: http://creativecommons.org/licenses/by-nc/4.0/.

ORCID iD

Louis Servaas Dolmans http://orcid.org/0000-0001-5255-3852

\section{REFERENCES}

1 Giles MF, Rothwell PM. Risk of stroke early after transient ischaemic attack: a systematic review and meta-analysis. Lancet Neurol 2007;6:1063-72.

2 Wu CM, McLaughlin K, Lorenzetti DL, et al. Early risk of stroke after transient ischemic attack: a systematic review and meta-analysis. Arch Intern Med 2007;167:2417-22.

3 Rothwell PM, Giles MF, Chandratheva A, et al. Effect of urgent treatment of transient ischaemic attack and minor stroke on early recurrent stroke (express study): a prospective population-based sequential comparison. The Lancet 2007;370:1432-42.

4 Lavallée $\mathrm{PC}$, Meseguer $\mathrm{E}$, Abboud $\mathrm{H}$, et al. A transient ischaemic attack clinic with round-the-clock access (SOS-TIA): feasibility and effects. Lancet Neurol 2007;6:953-60.

5 Rothwell PM, Algra A, Chen Z, et al. Effects of aspirin on risk and severity of early recurrent stroke after transient ischaemic attack and ischaemic stroke: time-course analysis of randomised trials. The Lancet 2016;388:365-75.

6 Moreau F, Asdaghi N, Modi J, et al. Magnetic resonance imaging versus computed tomography in transient ischemic attack and minor stroke: the more You see the more you know. Cerebrovasc Dis Extra 2013;3:130-6.

7 Förster A, Gass A, Kern R, et al. Brain imaging in patients with transient ischemic attack: a comparison of computed tomography and magnetic resonance imaging. Eur Neurol 2012;67:136-41.

8 Fonseca AC, Canhão P. Diagnostic difficulties in the classification of transient neurological attacks. Eur J Neurol 2011;18:644-8.

9 Amarenco P, Labreuche J, Lavallée PC. Patients with transient ischemic attack with $A B C D 2<4$ can have similar 90-day stroke risk as patients with transient ischemic attack with $A B C D 2 \geq 4$. Stroke 2012;43:863-5.

10 Amort M, Fluri F, Schäfer J, et al. Transient ischemic attack versus transient ischemic attack mimics: frequency, clinical characteristics and outcome. Cerebrovasc Dis 2011;32:57-64.

11 Dolmans LS, Kappelle LJ, Bartelink M-LE, et al. Delay in patients suspected of transient ischaemic attack: a cross-sectional study. BMJ Open 2019;9:e027161.

12 Dolmans LS, Rutten FH, El Bartelink M-L, et al. Serum biomarkers for the early diagnosis of TIA: the MIND-TIA study protocol. BMC Neurol 2015;15:119. 
13 Dolmans LS, Rutten FH, Koenen NCT, et al. Candidate biomarkers for the diagnosis of transient ischemic attack: a systematic review. Cerebrovasc Dis 2019;47:207-16.

14 Easton JD, Saver JL, Albers GW, et al. Definition and evaluation of transient ischemic attack: a scientific statement for healthcare professionals from the American heart Association/American stroke association stroke Council; Council on cardiovascular surgery and anesthesia; Council on cardiovascular radiology and intervention; Council on cardiovascular nursing; and the interdisciplinary Council on peripheral vascular disease. the American Academy of Neurology affirms the value of this statement as an educational tool for neurologists. Stroke 2009;40:2276-93.

15 Harrell FE, Lee KL, Califf RM, et al. Regression modelling strategies for improved prognostic prediction. Stat Med 1984;3:143-52.

16 Dambinova SA, Bettermann K, Glynn T, et al. Diagnostic potential of the NMDA receptor peptide assay for acute ischemic stroke. PLOS One 2012; 7:e42362.

17 Weissman JD, Khunteev GA, Heath R, et al. NR2 antibodies: risk assessment of transient ischemic attack (TIA)/stroke in patients with history of isolated and multiple cerebrovascular events. J Neurol Sci 2011;300:97-102.
18 Wunderlich MT, Hanhoff T, Goertler M, et al. Release of brain-type and heart-type fatty acid-binding proteins in serum after acute ischaemic stroke. J Neurol 2005;252:718-24.

19 Allard L, Burkhard PR, Lescuyer P, et al. Park7 and nucleoside diphosphate kinase $\mathrm{A}$ as plasma markers for the early diagnosis of stroke. Clin Chem 2005;51:2043-51.

20 Allard L, Turck N, Burkhard PR, et al. Ubiquitin fusion degradation protein 1 as a blood marker for the early diagnosis of ischemic stroke. Biomark Insights 2007;2:155-64.

21 Dutta D, Diagnosis of TIA. Diagnosis of TIA (DOT) score--design and validation of a new clinical diagnostic tool for transient ischaemic attack. BMC Neurol 2016;16:20.

22 Dawson J, Lamb KE, Quinn TJ, et al. A recognition tool for transient ischaemic attack. QJM 2009;102:43-9.

23 Lasserson DS, Chandratheva A, Giles MF, et al. Influence of general practice opening hours on delay in seeking medical attention after transient ischaemic attack (TIA) and minor stroke: prospective population based study. BMJ 2008;337:a1569.

24 Penn AM, Bibok MB, Saly VK, et al. Validation of a proteomic biomarker panel to diagnose minor-stroke and transient ischaemic attack: phase 2 of spectra, a large scale translational study. Biomarkers 2018;23:793-803. 